\title{
Market makers activity: behavioural and agent based approach
}

\section{Marcin Czupryna ${ }^{1}[0$}

Published online: 2 June 2020

(c) The Author(s) 2020

\begin{abstract}
The goal of this paper is to verify how behavioural and social features influence the decisions of market makers and to identify the impact that such decisions have on the trade volume, price levels and bid-ask spreads observed in the market. Many classical microstructural models explain the rational behaviour of market makers. We can distinguish two main groups of such models: information-based models and inventory-based ones. On the one hand, information-based models emphasise the role of the informational asymmetry between market makers and informed traders. On the other hand, inventory-based models relate the behaviour of market makers to the current status of inventories. In particular, the objective of the market maker is to either avoid bankruptcy or merely maintain an inventory balance. It is known, however, that it is not just rational factors which may influence economic behaviour. In particular, based on the literature, we stipulate that such personal traits as risk attitude, impulsivity, social behaviour and sense of fairness may influence market makers' behaviour. To verify this, we conducted a series of experiments with the goal of analysing the relation between these factors and market maker behaviour. Participants in these experiments played the role of a market maker in the simulated options market. Experimental data enabled us to analyse how the behavioural traits influence individual decisions. However, due to missing interactions among market makers during the experiment, the data did not enable us to analyse how these traits influence the aggregated observed markets parameters, such as trading volume and mean spread in a competitive market. Therefore, we propose a formal agent-based model that makes it possible to investigate how behavioural factors influence market variables such as price and volume by means of the simulation.
\end{abstract}

The Project has been financed by the Polish National Science Center within "Miniatura" Programme. Project No.: 2018/02/X/HS4/00251.

\footnotetext{
$凶 \quad$ Marcin Czupryna czuprynm@uek.krakow.pl

1 Cracow University of Economics, ul. Rakowicka 27, 31-510 Kraków, Poland
} 
Keywords Market maker - Agent based modelling · Behavioural finance

\section{Introduction}

The role of the market maker is to provide liquidity, by being ready to trade with other market participants (during an entire trading period). Market makers decide on the prices: the bid price (the price at which the market maker is ready to purchase an asset) and the ask price (the price at which the market maker is willing to sell). There is extensive empirical research and literature on the rational behaviour of market makers (Hasbrouck 2007; Madhavan 2002). Two main types of models are used in this respect: information-based and inventory-based De Jong and Rindi (2009) and O'hara (1997). The first group of models analyses the strategic decisions of market makers when dealing with other traders. A key characteristic of such traders is that they possess different levels of information regarding the potential future price of an asset (often classified as informed and uninformed/noise traders) in comparison with that of the market maker, such that an information asymmetry exists between market makers and traders, Glosten and Milgrom (1985). The second group of models analyses the role of inventories, assuming that maintaining a balance between asset and monetary inventories is the primary objective of the market maker (Stoll 1978). In a seminal paper on inventory-based models, Garman (1976) assumes that the objective of the market maker is to avoid bankruptcy. Therefore, market makers try both to maximise their earnings and to avoid bankruptcy. The optimal framework policy for this model framework was proposed by Amihud and Mendelson (1980). Their analysis shows that there is a preferred position for the market maker and that bid and ask prices are monotonic (decreasing) with inventory balance. In particular, it is optimal for a marker maker to monotonically increase the ask price (in order to decrease selling) and simultaneously increase the bid price (in order to increase buying) when the inventory balance is negative. Analogously, it is optimal for a marker maker to monotonically decrease the ask price (in order to increase selling) and simultaneously decrease the bid price (in order to decrease buying) when the inventory balance is positive. The magnitude of price adjustments necessary for increasing and decreasing trades may differ. Such a policy aims at both profit maximisation and maintaining the inventory balance. Since these goals are the same as the goals of participants in the experiment with the usage of a simulated market makers environment, we will use this framework for the results analysis.

The behavioural factors, such as perception of prior information (optimistic/pessimistic bias) or perception of private signal noise (overconfidence/underconfidence bias) may also influence market makers behaviour. Such factors may nonetheless lead to better performance than that of purely rational market makers, in addition to influencing both trading volume and prices, Germain et al. (2014). Similarly, Harris and Panchapagesan (2005) study the informational content of order books and how market makers use such information. In contrast, Chakrabarty and Moulton (2012) study the limiting role of attentional capacity upon market makers behaviour.

Based on the literature, we stipulate that personal traits such as numeracy skills, attitude to risk, impulsivity, and social behaviour (sense of fairness) may also influence 
market makers' behaviour. Therefore, we conducted a series of experiments to measure the extent of these personal traits. In particular, we used a Balloon Analogue Risk Task (Lejuez et al. 2002), an ultimatum game (Harlé and Sanfey 2010), and a response game (Brocklebank et al. 2011), in addition to measuring the level of conservatism (Garety et al. 1991), the level of impulsiveness (Whiteside and Lynam 2001; Cyders et al. 2007), and both objective and subjective numeracy skills (Lipkus et al. 2001; Fagerlin et al. 2007). In order to analyse the relation between these factors and market maker behaviour, we also allowed the experimental participants to play the role of market makers in a simulated environment. The participants were trading with financial contracts: put and call options.

The behaviour of market makers is often studied empirically in the context of liquidity, e.g. Korajczyk and Murphy (2018) and Goldstein and Hotchkiss (2019) or market regulations, e.g. Cimon and Garriott (2019). Since, during the course of the experiment, participants played in a non-competitive market (played against a computer) we have used the simulation approach to analyse the impact of behavioural traits upon the observed liquidity (measured by the bid-ask spread) and traded volume in a competitive environment (market makers compete against each other). In particular, we have constructed an agent-based model with heterogeneous agents and a set of decision rules derived on the basis of experimental results. Use of an agent-based approach also allowed us to investigate the impact of behavioural traits to a greater degree than was possible during the experiment itself.

The paper is organised as follows. In the following section we present the design of the experiment and the results obtained. Then we present the proposed formalisations of the impact of behavioural traits upon the behaviour of market makers, together with the agent-based model design and results. The conclusions are given in the final section.

\section{Behavioural approach}

We first conducted a series of laboratory experiments to observe and measure the behaviour of market makers ${ }^{1}$ in a simulated market as well as the magnitude of the selected personal traits. Then, using econometric methods, we examined the relationship between the observed market makers behaviour and their personal traits.

\subsection{Experiment design}

To observe the market makers behaviour, we used the volcube platform (Market Squared Ltd 2010), which is a dedicated platform for training potential market makers in options markets. The users trade with a given number of European option contracts having different strike prices during the training sessions. The current option contracts position, risk, option risk parameters (the so-called Greeks), as well as the current and potential profit/loss are observed during a session. A user performs the role of a mar-

\footnotetext{
${ }^{1}$ Students of a Financial Markets major participated in the experiments during the Financial Engineering course.
} 
ket maker and decides on the bid and ask prices, together with corresponding trading volumes. This is done in the form of a structured dialogue. As an example, we briefly present a sample dialogue between the market maker (MM) and a computerised trader (T).

1. T: APR 100 puts? - a trader asks for a price quote of a European put option with a strike price of 100 and a maturity in April.

2. MM: $3.14 / 3.16,125$ by 125 -a market maker offers to buy 125 option contracts at a price of 3.14 or to sell 125 option contracts at a price of 3.16 .

3. T: I can pay 3.16 for 300 - a trader discloses his or her intention to buy 300 put option contracts at 3.16 .

4. MM: Sell the APR 100 puts at 3.16-a market maker sells 100 option contracts at 3.16 .

A single game (or trading session) lasts 25 rounds, although it may finish earlier if the participant exceeds the risk limit. This happens when the absolute value of a market maker position (positive when the market maker has a long position and negative when short) exceeds the limit for several consecutive trading rounds. We measure market maker activity in terms of the bid and ask spreads quoted, the risk taken and the transactions concluded. Additionally, we conducted a series of classical experiments that are available in the INQUISIT software test library (Millisecond Software LLC 1999).

- Balloon Analogue Risk Task (Lejuez et al. 2002): a participant pumps a computerized balloon in a stepwise manner. Each additional pump may provide incremental earnings but also increase the risk of the balloon bursting, with the resultant loss of all the earnings accumulated to that point. A participant is free to collect earnings at any time. We measured the average number of balloon pumps when the balloon did not burst. This average number measures the propensity towards risk-taking.

- Ultimatum game, Harlé and Sanfey (2010): a participant decides on how to share a fixed amount of points between himself or herself and another participant, who may either accept or decline the proposal. Participants played both roles: proposer and responder. The average amount proposed measures the sense of fairness, whereas the average amount that was rejected measures the reaction to unfairness.

- Response game, Brocklebank et al. (2011): a participant decides between two options. In the first option, a participant decides on the amount of points for him or her and a co-player. In the second option, a participant lets the co-player decide between two options (each option is characterised by the amount of points the participant and a co-player receive). The total amount of points earned in this game measures the ability to think strategically.

- Bead task, Garety et al. (1991): a participant observes two urns which both contain beads of two given colours. In each urn, the two possible colours of beads are in different proportions. One by one, beads selected from one particular urn are presented to a participant, who does not know which urn is being used to select beads from. The number of beads necessary for the participant to make a decision regarding which urn the beads are selected from measures conservatism.

Furthermore, we distributed computerised Polish versions of the following questionnaires: 
- UPPS-P Impulsive Behaviour Scale, Whiteside and Lynam (2001); Cyders et al. (2007), which measures five traits: negative urgency (acting rashly under negative emotions), positive urgency (acting rashly under positive emotions), lack of premeditation, lack of perseverance and sensation seeking. We have used a Polish adaptation of the scale, Poprawa (2016).

- ONS (Objective Numeracy Skills) scale, Lipkus et al. (2001)

- SNS (Subjective Numeracy Skills) scale, Fagerlin et al. (2007)

All the measures of the personality traits were normalised between 0 and 1 , in such a way that the minimum observed value is scaled to 0 and the maximum value is scaled to 1 .

\subsection{Experiment data and methodology}

Students of a Financial Markets major participated in the experiments during a course on Financial Engineering in the summer semester of 2016. Training was provided to the students during the course. Finally, we used data collected during the trading competition organised for students at the end of the course on 15th of June 2016. Although participation was voluntary, such participation (including the results achieved) provided additional points and subsequently higher grades. This represented a strong motivating factor for the students. 68 students (40 women and 28 men) participated in the competition, with a total of 10,967 dialogues observed. The student group was homogenous with respect to age, all but a few students were of similar age, 21 years old. The relevant accompanying experiments were conducted in march and April 2016 using INQUISIT software (Millisecond Software LLC 1999), while UPPS-P, ONS and SNS questionnaires on behavioural traits were collected in April 2016 using the LimeSurvey software ( $\mathrm{GmbH} 2012)$. All experiments were conducted in Cracow.

We applied a series of generalised linear mixed models (McCulloch and Neuhaus 2005) to analyse the impact of behavioural traits on the selected features of market maker behaviour. The final models were selected using the Akaike Information Criterion. We used the R package glmmTMB (Brooks et al. 2017) for model estimation and the R package muMIn (muMIn 2019) for the final model selection.

In particular, we analysed the following dimensions of market maker behaviour using regression analysis:

- Total spread width: difference between ask and bid prices with zero (optimal) balance position

- Spread adjustment rate to discourage unwanted trades: market makers having short-negative-position proportionally increase the ask price to discourage further selling; analogously, market makers having long-positive-position decrease the bid price to discourage further buying

- Spread adjustment rate to encourage desired trades: market makers having shortnegative-position proportionally increase the bid price to encourage buying in order to balance their position; similarly, market makers having long-positiveposition decrease the ask price to encourage selling for the same purpose

- Probability of accepting offers with less favourable prices: brokers may either accept the market maker price, obliging them to make a deal, or submit a coun- 
Table 1 Spread width for balanced positions

\begin{tabular}{lclcl}
\hline & Estimate & SE & z Value & $\operatorname{Pr}(>|z|)$ \\
\hline (Intercept) & 0.682 & 0.327 & 2.086 & 0.037 \\
Conservatism & 0.350 & 0.241 & 1.450 & 0.147 \\
Fairness & -0.589 & 0.263 & -2.244 & 0.025 \\
Negative urgency & 1.505 & 0.374 & 4.030 & 0.000 \\
Objective numeracy skills & 0.548 & 0.209 & 2.619 & 0.009 \\
Lack of perseverance & 0.670 & 0.361 & 1.858 & 0.063 \\
Positive urgency & -0.702 & 0.241 & -2.913 & 0.004 \\
Strategic thinking & -0.729 & 0.236 & -3.084 & 0.002 \\
\hline
\end{tabular}

teroffer that is worse, from the market maker perspective, i.e. lower than ask or higher than bid quoted originally by the market maker. In simpler terms, a broker may still want to buy an option but at a lower price than the price quoted initially by market maker. Alternatively, a broker may still want to sell an option but at a higher price than the price quoted initially by a market maker.

- Share of additional volume accepted: brokers may counter propose a transaction volume that is higher than that initially offered by the market maker; although market makers are only obliged to trade the originally proposed volume, they can nevertheless trade any volume up to the limit established by the broker's proposal.

The dimension selection was inspired by theoretical considerations about rational market maker behaviour (Amihud and Mendelson 1980) and the structure of dialogues in the game. The spread is normalised by one of the option risk parameters (vega), since setting the spread to the value of one vega is recommended during the training.

\subsection{Experiment results}

The individual results of regression analyses are presented in Tables 1, 2, 3, 4, and 5. For example, in examining the regression results presented in Table 1 it becomes evident that a sense of fairness decreases the quoted spread (the better the quoted price for market makers, the worse it is for brokers trading with them), as well as strategic thinking (a lower spread means a higher probability of acceptance). On the other hand, a higher level of objective numeracy skills increased the quoted spread.

In order to interpret the regression results presented in Tables 2 and 3, it should be noted that the more negative the estimated parameter value, the higher the adjustment rate (the stronger reaction) is to the imbalanced trading position. For example, one can observe that negative urgency and lack of perseverance increase the reaction to imbalance (potential overreaction), whereas fairness (a participant may try to avoid quoting prices unfair to the broker), subjective numeracy skills and lack of premeditation (a participant may ignore imbalance) decrease the reaction to imbalance.

None of the behavioural traits under consideration influence the spread adjustment rate to encourage trades that lead to reduction of the trade position imbalance, see Table 3 . 
Table 2 Spread adjustment rate to discourage unwanted trades

\begin{tabular}{lrrrr}
\hline & Estimate & SE & z value & $\operatorname{Pr}(>|z|)$ \\
\hline Intercept) & -0.207 & 0.084 & -2.451 & 0.014 \\
Fairness & 0.172 & 0.057 & 3.022 & 0.003 \\
Negative urgency & -0.162 & 0.073 & -2.218 & 0.027 \\
Objective numeracy skills & -0.122 & 0.044 & -2.780 & 0.005 \\
Lack of perseverance & -0.124 & 0.079 & -1.564 & 0.118 \\
Lack of premeditation & 0.166 & 0.068 & 2.443 & 0.015 \\
Subjective numeracy skills & 0.163 & 0.055 & 2.964 & 0.003 \\
Strategic thinking & 0.179 & 0.050 & 3.603 & 0.000 \\
\hline
\end{tabular}

Table 3 Spread adjustment rate to encourage wanted trades

\begin{tabular}{lllll}
\hline & Estimate & $\mathrm{SE}$ & $\mathrm{z}$ value & $\operatorname{Pr}(>|\mathrm{z}|)$ \\
\hline (Intercept) & -0.010 & 0.009 & -1.102 & 0.270 \\
\hline
\end{tabular}

Table 4 Probability of accepting offers with worse price conditions

\begin{tabular}{lrrrr}
\hline & Estimate & \multicolumn{1}{l}{ SE } & z value & $\operatorname{Pr}(>|\mathrm{z}|)$ \\
\hline (Intercept) & -1.252 & 0.686 & -1.826 & 0.068 \\
Broker intent & 0.707 & 0.110 & 6.406 & 0.000 \\
Fairness & -1.083 & 0.632 & -1.714 & 0.087 \\
Positive urgency & 1.483 & 0.488 & 3.037 & 0.002 \\
Skew broker & 1.536 & 0.134 & 11.495 & 0.000 \\
Subjective numeracy skills & 1.103 & 0.595 & 1.854 & 0.064 \\
Strategic thinking & 1.770 & 0.526 & 3.366 & 0.001 \\
\hline
\end{tabular}

We have also fitted the binary regression using the logistic link function, see Table 4. The broker intent variable is a binary variable that assumes the value 1 if the trade would lead to an imbalance decrease and 0 otherwise. The skew broker variable represents the difference between the market maker's initially quoted ask/bid price and the counter-offer proposed by a broker. ${ }^{2}$ The lower (more negative) the value, the greater is the difference between these two prices to the disadvantage of the market maker. Only the sense of fairness decreases the probability of acceptance, by a market maker, of a broker price with worse conditions.

None of the behavioural traits under consideration influence the share of additional volume accepted, see Table 5.

In order to verify whether there may be socio-economic aspects related to differences in the regression results (gender differences in this case, as the group was relatively homogenous with respect to other factors such as age, educational level,

\footnotetext{
2 The difference between a broker price and an ask price if a broker wants to buy. Accordingly the difference between a bid price and a broker price if a broker wants to sell.
} 
Table 5 Share of additional volume accepted

\begin{tabular}{lccrc}
\hline & Estimate & SE & z value & $\operatorname{Pr}(>|z|)$ \\
\hline (Intercept) & 0.130 & 0.035 & 3.739 & 0.000 \\
Broker intent & 0.071 & 0.012 & 5.947 & 0.000 \\
Skew broker & -0.067 & 0.018 & -3.661 & 0.000 \\
\hline
\end{tabular}

social status), we ran the same regressions with a binary variable representing gender, which was added to the regression models as an explanatory variable. In none of the models was the additionally estimated parameter for the gender variable significant, and significance levels varied from 0.165 to 0.702 .

\subsection{Experiment benchmark}

For validation of the results, the data from the experiment in which students participated was compared with the sample data obtained from vocational training done by the professional traders (63 participants and 41,031 rounds in total). This data was collected in the second half of the year 2017 during the training for the Futures Commissions Merchants (FCM) in China. The vast majority of the traders were at the same level as junior traders. The simulations formed part of their assessment.

The provided data was anonymised and nothing other than the trading data (on behavioural traits) was available. Therefore, we only used the professional subgroup variable (a binary variable that takes the value 1 if a participant was a professional trader and 0 otherwise). Additionally the remaining variables, whose value can be calculated only on the basis of trading data received, were also used in the subsequent regression analysis. Using a binary variable to represent whether the trader is experienced or not (in the case of students) represents a simplification compared to using a more diverse scale such as years of trading, for instance. However, we possess no data that would enable us to construct such a scale. The regression analysis was run on the merged data, comprising both sets of trading data for students and professional traders. The professional subgroup variable was not significant in the case of the first ( $p$ value 0.599) — Table 6, second (0.542) — Table 7, third (0.936) - Table 8, fourth (0.863) — Table 9, and fifth (0.377) - Table 10 regression. The only significant differences were the interaction terms between the professional subgroup variable and skew broker variable and between the professional subgroup variable and broker intent variableTable 9. The broker intent variable is a binary variable that takes the value 1 if the trade would lead to an imbalance decrease and 0 otherwise. The imbalance variable is a variable representing the absolute value of the position imbalance. The skew broker variable represents the difference between the market maker initially quoted ask/bid price and the counter-offer proposed by a broker. Professionals were more likely to accept broker proposals with less favourable prices. 
Table 6 Spread width for balanced positions - merged data

\begin{tabular}{lcccc}
\hline & Estimate & SE & z value & $\operatorname{Pr}(>|z|)$ \\
\hline (Intercept) & 0.987 & 0.050 & 19.845 & 0.000 \\
Professional & 0.035 & 0.067 & 0.526 & 0.599 \\
\hline
\end{tabular}

Table 7 Spread adjustment rate to discourage unwanted trades-merged data

\begin{tabular}{lcccc}
\hline & Estimate & SE & z value & $\operatorname{Pr}(>|z|)$ \\
\hline (Intercept) & -0.054 & 0.013 & -4.151 & 0.000 \\
Professional & 0.011 & 0.018 & 0.610 & 0.542 \\
\hline
\end{tabular}

Table 8 Spread adjustment rate to encourage desired trades—-merged data

\begin{tabular}{lcccc}
\hline & Estimate & SE & z value & $\operatorname{Pr}(>|z|)$ \\
\hline (Intercept) & -0.013 & 0.012 & -1.155 & 0.248 \\
Professional & 0.001 & 0.015 & 0.080 & 0.936 \\
\hline
\end{tabular}

Table 9 Probability of accepting offers with less favourable price conditions-merged data

\begin{tabular}{lrrrc}
\hline & Estimate & \multicolumn{1}{l}{ SE } & $\mathrm{z}$ Value & $\operatorname{Pr}(>|\mathrm{z}|)$ \\
\hline (Intercept) & 0.299 & 0.127 & 2.363 & 0.018 \\
Professional & -0.028 & 0.164 & -0.172 & 0.863 \\
Skew broker & 1.505 & 0.089 & 16.857 & 0.000 \\
Broker intent & 0.625 & 0.072 & 8.659 & 0.000 \\
Imbalance & -0.000 & 0.000 & -0.626 & 0.531 \\
Professional:skew broker & -1.400 & 0.090 & -15.537 & 0.000 \\
Professional:broker intent & -0.373 & 0.079 & -4.740 & 0.000 \\
Professional:imbalance & 0.000 & 0.000 & 0.476 & 0.634 \\
\hline
\end{tabular}

Table 10 Share of additional volume accepted—merged data

\begin{tabular}{lrrrc}
\hline & Estimate & SE & $\mathrm{z}$ Value & $\operatorname{Pr}(>|\mathrm{z}|)$ \\
\hline (Intercept) & 0.131 & 0.020 & 6.512 & 0.000 \\
Professional & 0.025 & 0.028 & 0.883 & 0.377 \\
Skew broker & -0.023 & 0.015 & -1.594 & 0.111 \\
Broker intent & 0.089 & 0.010 & 8.901 & 0.000 \\
Imbalance & 0.000 & 0.000 & 1.512 & 0.130 \\
Professional:skew broker & 0.023 & 0.015 & 1.554 & 0.120 \\
Professional:broker intent & 0.001 & 0.011 & 0.078 & 0.938 \\
Professional:imbalance & -0.000 & 0.000 & -0.227 & 0.821 \\
\hline
\end{tabular}




\section{Simulation approach}

We first describe the agent-based model used and then the results obtained from the simulation. The agent-based model is inspired by the volcube game framework, which additionally allows agents to compete against each other. Additional theoretical considerations, which provide an extension to the model introduced by Amihud and Mendelson (1980) are presented in Sect. 1.

\subsection{Agent based model}

We consider two types of agents in the model: 200 heterogeneous market makers and 2000 brokers. Brokers can be connected to a certain number (used as a parameter $n$ in the simulation) of market makers.

Each broker is endowed with 1000 options (each option was randomly specified as a call or a put with the same probability) that he or she would like to trade (for each option, a broker intention was randomly specified for whether to buy or to sell, with identical probability). Each option has an internal value for a broker, expressed as the difference from the (mid) option price. It is higher if a broker wishes to buy an option and lower otherwise. The difference is expressed in multiples of the option vega parameter and has a "log-normal" distribution with a minimum of 0 and a mean value and standard deviation both equal to 1 . Similarly, the desirable contract size is also a truncated log-normal distribution with a minimum value of 100 and both the mean value and standard deviation also equal to 100 . We have assumed an option price value of 1.63 and an option vega of 0.09 . These two values are parameterised based on the volcube data.

Market makers are endowed with decision rules implemented by the econometric models estimated previously, see Tables 1, 2, 3, 4, and 5. We considered nine personal traits: conservatism, fairness, negative and positive urgency, objective and subjective numeracy skills, lack of perseverance, lack of premeditation, and strategic thinking in the simulation. Each of these personal traits is used as an explanatory variable in at least one of the econometric models. Thus, for each $i$ market maker, his or her personal traits have a mathematical representation as a nine-element vector $\mathbf{x}_{\mathbf{i}}=\left[x_{i 1}, x_{i 2}, \ldots, x_{i 9}\right]$, having $x_{i j} \in[0,1]$ for $j=1,2, \ldots 9$. Each market maker may have a different set of values of personal traits. As there are 200 market makers under consideration in the simulation, we also considered 200 different parameter sets, representing different values of the behavioural traits considered in the simulation. The values of the vectors $\mathbf{x}_{\mathbf{i}}, i=1,2, \ldots, 200$ are set by systematically searching the parameter space using the Sobol numbers (Bratley and Fox 1988; Christophe and Petr 2014). In particular, each vector $\mathbf{x}_{\mathbf{i}}$ is an $i$-th element of the 9-dimensional Sobol sequence. We could have potentially used the empirical distribution of the values of behavioural traits, which is observed for the experimental participants instead. However, using the Sobol sequence enables us to conduct a more systematic statistical analysis of the impact of personal traits on the observed variables.

The simulation steps are as follows:

- a broker collects offers from connected market makers and selects the best offer 
Table 11 Number of trades before ruin

\begin{tabular}{lrrrr}
\hline & Estimate & \multicolumn{1}{l}{ SE } & t value & $\operatorname{Pr}(>|t|)$ \\
\hline (Intercept) & 133.8176 & 4.5431 & 29.46 & 0.0000 \\
$n$ & -3.3708 & 0.2257 & -14.94 & 0.0000 \\
$k$ & 22.0203 & 0.6227 & 35.36 & 0.0000 \\
Conservatism & -48.4556 & 2.4715 & -19.61 & 0.0000 \\
Fairness & 58.3114 & 2.4776 & 23.54 & 0.0000 \\
Negative urgency & -160.6079 & 2.7072 & -59.33 & 0.0000 \\
Objective numeracy skills & -68.9488 & 2.4886 & -27.71 & 0.0000 \\
Lack of perseverance & -73.3940 & 2.4605 & -29.83 & 0.0000 \\
Positive urgency & 71.1338 & 2.5013 & 28.44 & 0.0000 \\
Lack of premeditation & 8.8884 & 2.4687 & 3.60 & 0.0003 \\
Subjective numeracy skills & -11.4135 & 2.4423 & -4.67 & 0.0000 \\
Strategic thinking & 99.2536 & 2.5231 & 39.34 & 0.0000 \\
\hline
\end{tabular}

- a broker and selected market maker deal together

- if a market maker exceeds a risk limit for $k$ (used as a parameter) simulation steps, he or she leaves the market

The model is implemented in Java, using the MASON 19 framework. We considered the following values of the parameter $k=0,1,2,3$ and parameter $n=5,6, \ldots, 15$. We ran 4 simulations for each parameter set, thus we have explored $4 \times 11 \times 4=176$ simulations in total. The number of simulation steps in a single simulation was set to 1000. We recorded total profits and the simulation step in which a market maker was ruined (if it happened during the course of the simulation).

We applied stepwise linear regression for each of the regression results presented subsequently in this paragraph. The "backward" direction was used in the stepwise regression, as well as the Akaike Information Criterion for the final model selection. In the first model, we regressed the number of trades before a market maker went bankrupt (we only considered such market makers) on the simulation parameters, see Table 11. We can observe that both the ability to think strategically, positive urgency and the trait of fairness - and to a much lesser extent lack of premeditation (more intuitive thinking) — increase the chances of survival in the market.

In the second model, we regressed the average financial result per simulation step (when still active in the market) on the simulation parameters, see Table 12. We can observe that positive urgency and the ability to think strategically, and to a lesser extent the sense of fairness, all increase the average financial outcome.

In the third model, we regressed the number of transactions concluded per simulation step (when a market maker is still active in the market) on the simulation parameters, see Table 13 . We can see that both fairness and the ability to think strategically, and to a lesser extent positive urgency and subjective numeracy skills, increase the number of transactions conducted.

We also analysed how the behavioural traits under consideration influence the market. For this purpose, we increased the value of the selected behavioural trait (only 
Table 12 Average financial results per simulation step and market maker

\begin{tabular}{lrrrr}
\hline & Estimate & SE & t value & $\operatorname{Pr}(>|t|)$ \\
\hline Intercept) & 32.1718 & 0.3616 & 88.97 & 0.0000 \\
$n$ & -1.0054 & 0.0174 & -57.70 & 0.0000 \\
$k$ & -0.7207 & 0.0493 & -14.62 & 0.0000 \\
Conservatism & -4.1671 & 0.1921 & -21.69 & 0.0000 \\
Fairness & 5.1120 & 0.1927 & 26.53 & 0.0000 \\
Negative urgency & -20.0495 & 0.1916 & -104.62 & 0.0000 \\
Objective numeracy skills & -5.5177 & 0.1933 & -28.55 & 0.0000 \\
Lack of perseverance & -6.5940 & 0.1921 & -34.33 & 0.0000 \\
Positive urgency & 8.1272 & 0.1927 & 42.19 & 0.0000 \\
Lack of premeditation & -2.5221 & 0.1911 & -13.20 & 0.0000 \\
Subjective numeracy skills & -3.6013 & 0.1924 & -18.72 & 0.0000 \\
Strategic thinking & 7.0437 & 0.1934 & 36.43 & 0.0000 \\
\hline
\end{tabular}

Table 13 Average trades per simulation step and a market maker

\begin{tabular}{lrrrr}
\hline & Estimate & SE & t value & $\operatorname{Pr}(>|\mathrm{t}|)$ \\
\hline (Intercept) & 18.2993 & 0.3924 & 46.63 & 0.0000 \\
$n$ & 0.1001 & 0.0193 & 5.18 & 0.0000 \\
Conservatism & -4.2774 & 0.2130 & -20.08 & 0.0000 \\
Fairness & 13.1333 & 0.2136 & 61.49 & 0.0000 \\
Negative urgency & -25.5584 & 0.2125 & -120.30 & 0.0000 \\
Objective numeracy skills & -11.4802 & 0.2142 & -53.58 & 0.0000 \\
Lack of perseverance & -13.9647 & 0.2130 & -65.57 & 0.0000 \\
Positive urgency & 6.2888 & 0.2136 & 29.44 & 0.0000 \\
Lack of premeditation & -0.7735 & 0.2119 & -3.65 & 0.0003 \\
Subjective numeracy skills & 1.9837 & 0.2133 & 9.30 & 0.0000 \\
Strategic thinking & 15.0011 & 0.2144 & 69.98 & 0.0000 \\
\hline
\end{tabular}

those traits that were significant in at least one of the econometric models are considered) by 0.25 for each market maker (entire population). The results in terms of average (standard deviation) trading volume, and spread ${ }^{3}$ are given below (Table 14).

\section{Conclusions and further research}

Although there is extensive literature regarding the rational behaviour of market markers, i.e. optimal with respect to expected profit and risk taken, there are fewer studies on their actual behaviour in a genuine trading environment. This field of research

\footnotetext{
${ }^{3}$ We use the term spread here for the absolute difference between the option mid-price and the bid or ask price respectively. 
Table 14 Average trading volume and spread per simulation step

\begin{tabular}{lccll}
\hline Trait increased & Mean volume & sd volume & Mean spread & sd spread \\
\hline None & $216,631.6$ & 7776.4 & 0.047 & 0.028 \\
Conservatism & $215,000.4$ & 8146.6 & 0.053 & 0.030 \\
Fairness & $219,863.6$ & 5922.4 & 0.024 & 0.017 \\
Negative urgency & $200,309.0$ & $10,979.7$ & 0.117 & 0.049 \\
Objective numeracy skills & $208,662.4$ & 9253.2 & 0.079 & 0.039 \\
Lack of perseverance & $208,217.2$ & 9565.7 & 0.082 & 0.040 \\
Positive urgency & $219,715.0$ & 7132.5 & 0.037 & 0.024 \\
Lack of premeditation & $218,531.3$ & 6377.1 & 0.029 & 0.020 \\
Subjective numeracy skills & $218,548.3$ & 6473.1 & 0.030 & 0.021 \\
Strategic thinking & $220,465.6$ & 5699.6 & 0.023 & 0.017 \\
\hline
\end{tabular}

also takes into account that market makers may not be purely rational and that their decisions may be influenced by the market makers personal traits and associated decision biases. The common methods used are either building theoretical models that explicitly take into account biases (Germain et al. 2014), or statistically analysing the trading data (Chakrabarty and Moulton 2012). Though the former type of method may identify the individual decision mechanism that may lead to the observed market behaviour, they require simplifications. The latter kind of method analyses the actual relations between market variables but may fail to identify the individual decision mechanisms underlying these relations. Given these respective limitations, we have followed a different approach. Namely, we began by analysing and identifying the market makers' decisions and then related them to specific individual traits. In particular, by designing and conducting such an experiment, we identified nine behavioural traits (conservatism, fairness, negative urgency, positive urgency, objective numeracy skills, subjective numeracy skills, lack of perseverance, lack of premeditation, strategic thinking) that may influence different dimensions of market maker behaviour. In the second phase of our approach, we related individual market makers decisions to the observed market-wide parameters using an agent-based approach. In particular, by means of computer simulations (a formal agent-based model), we have identified that the ability to think strategically, and to a lesser extent positive urgency and a sense of fairness, serve to increase both the probability of survival in the market and the profitability of a market maker. In the final part of the research, presented in the Appendix, we use mathematical models to show, in a more formal way, how the market maker's behavioral traits may influence his or her decisions. This may provide a base for building theoretical models that relate behavioural traits to market parameters. We also envisage that a potential future research possibility lies in analysing real market data by comparing it to the simulation results. This would potentially provide some behavioural justification for the identified and observed market inefficiencies.

Acknowledgements I would like to thank the participants of the Modelling and Simulation of SocialBehavioural Phenomena in Creative Societies Conference (MSBC-2019) for their valuable comments and discussions during the conference. I am very grateful to Chris Jenkins and Market Squared Ltd. for enabling 
access to the volcube program, provision of the data and support during the experiment. I am also very thankful to Timothy Harrell for his advice concerning matters of English usage.

Open Access This article is licensed under a Creative Commons Attribution 4.0 International License, which permits use, sharing, adaptation, distribution and reproduction in any medium or format, as long as you give appropriate credit to the original author(s) and the source, provide a link to the Creative Commons licence, and indicate if changes were made. The images or other third party material in this article are included in the article's Creative Commons licence, unless indicated otherwise in a credit line to the material. If material is not included in the article's Creative Commons licence and your intended use is not permitted by statutory regulation or exceeds the permitted use, you will need to obtain permission directly from the copyright holder. To view a copy of this licence, visit http://creativecommons.org/licenses/by/4.0/.

\section{Appendix}

In the appendix we first propose more formalised methods for describing the impact of personal traits on the behaviour of market makers. Then we present the results of some simulations of market makers' behaviour and the consequences for mean earnings and probability of ruin. The starting point for this analysis is the article of Amihud and Mendelson (1980) and the analysis can be seen as an extension of the previous work on the behaviour of rational market makers.

We assume that a market maker buys and sells a financial instrument (short selling is also possible) and is constrained by defined risk limits. If the risk limit is exceeded, a market maker goes bankrupt. Brokers approach market makers with either an intention to buy or to sell. Both situations are equally possible and independent of the quoted bid and ask prices (a broker first approaches a market maker with a predetermined intention to buy or sell and only then asks for a quote). Then, depending on the value of the relevant spread (which is measured as the difference between the ask price and mid-price if a broker wants to buy or the difference between the mid-price and bid price if a broker wants to sell) the probability of concluding a transaction is calculated.

We assume that a trade probability (demand) function is linear, see Fig. 1. Only one unit of a financial instrument may be traded in an individual transaction between a broker and a market maker. As a consequence, one can see that for a perfectly balanced position, market makers maximise their expected results by setting the spread value to 1 . Such a value is recommended during the training available in a volcube program. Analogous demand curves can be estimated, based on either the experiment results (see Table 15 for the regression results) or simulation results. We have decided to use the theoretical demand curve because of its properties: the fact that expected profit takes the maximum value for the spread value of 1 , which is an assumed value quoted by a rational market maker, and the fact that it takes the value 0 for a spread value of 2, which is an assumed spread value for a rational market maker to prevent unwanted trades when at the risk limit. Such trades could eventually lead to a default (bankruptcy).

Based on Amihud and Mendelson (1980), we have assumed that both the ask and bid curves are monotonic, with values 0 and $2(-2)$ respectively, at the risk limits. This ensures that risk limits cannot be exceeded for an assumed demand function. We assumed the following functional form of the bid and ask curves, as described in Eq. 1, 
Table 15 Estimated parameters of the demand curve

\begin{tabular}{lrrrr}
\hline & Estimate & SE & t value & $\operatorname{Pr}(>|\mathrm{t}|)$ \\
\hline (Intercept) & 0.8037 & 0.0044 & 183.58 & 0.0000 \\
Spread & -0.1031 & 0.0073 & -14.21 & 0.0000 \\
\hline
\end{tabular}

Fig. 1 Demand function

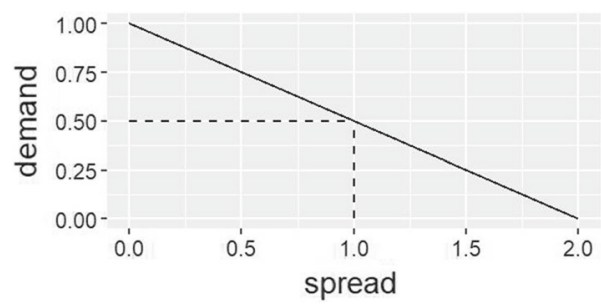

$x$ stands for the ratio of the position value to the absolute value of the risk limit and admits values from the closed interval $[-1,1]$, moreover we consider $n>0$.

$$
\operatorname{bid}=-\operatorname{sgn}(\mathrm{x}) \times|x|^{n}-1 \text { ask }=-\operatorname{sgn}(\mathrm{x}) \times|x|^{n}+1
$$

Initially, we considered different potential values of parameter $n$, namely $n \in$ $\{1 / 10,1 / 9, \ldots, 9,10\}$. We also initially considered different potential values for the risk limit parameter $r_{l} \in\{3,5,7,9\}$ and different potential values for the number of rounds played, denoted by $r_{m} \in\{25,50, \ldots, 475,500\}$. Finally, we set the value of $n$ parameter to 3 , since for this parameter value market maker profit was maximal in most of the scenarios defined by the values of parameters $r_{l}$ and $r_{m}$. Then we fixed the risk limit value $r_{l}=5$ and the number of rounds played value $r_{m}=200$. These two parameter values were selected in such a way that there is a non-negligible probability of a market maker reaching the limits. The bid and ask curves for the selected value of parameter $n$ is presented in Fig. 2 .

We then formalised the impact of behavioural traits on market maker behaviour by adjusting the market maker bid and ask curves accordingly, see Table 16. We will denote by $u$ a uniformly distributed random variable, which admits values in the range $(-\sigma / 2, \sigma / 2)$, where $\sigma$ is a parameter. $r<r_{m}$ denotes the number of a consecutive round of trading, while $\tilde{x}$ denotes the position value which results from substitution of the current position by a value that is shifted by an increment of 1 towards 0 . We will also denote the bid curve defined by Eq. 1 as $b$ for brevity. For the same reason, only the bid curves are presented in Table 16 as the ask curves are adjusted analogously.

We have used a random variable $u$ to represent positive urgency (a market maker quotes inaccurately when having a trading position which is close to the perfectly balanced position), negative urgency (a market maker quotes inaccurately when having a trading position which is close to the risk limit position), lack of premeditation (a market maker quotes inaccurately during trading but with the same level of inaccuracy regardless of the current trading position) and lack of perseverance (a market maker quotes inaccurately, with the inaccuracy level increasing with trading time). We have also used modified bid and ask curves: a constant -1 for sensation seeking (a market 
Fig. 2 Bid and ask prices

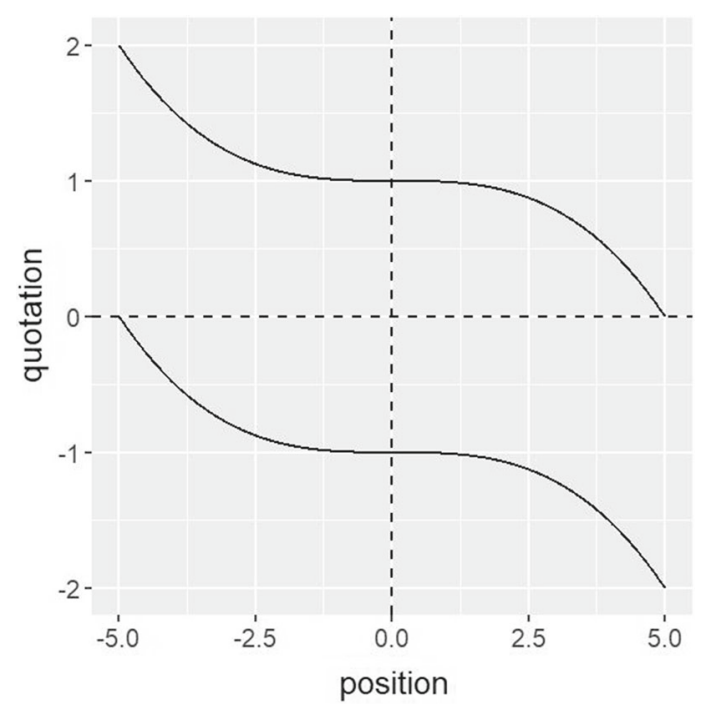

Table 16 Bid and ask curves for different behavioural traits

\begin{tabular}{lll}
\hline Trait & Description & Bid curve \\
\hline Rational & Profit maximising & $b=-x^{3}-1$ \\
Positive urgency & Acting hastily under positive emotions & $b+u$ if $|x|<0.5$ and $b$ if $|x|>0.5$ \\
Negative urgency & Acting hastily under negative emotions & $b$ if $|x|<0.5$ and $b+u$ if $|x|>0.5$ \\
Lack of premeditation & Acting without thinking & $b+u / 2$ \\
Lack of perseverance & Tendency not to remain focused & $b+u * \frac{r}{r_{m}}$ \\
Sensation seeking & Seeking thrilling experiences & 1 \\
Risk avoidance & Not taking enough risk & $-\operatorname{sgn}(\mathrm{x})|x|^{2}-1$ \\
Lack of strategic thinking & No forward thinking & $-\tilde{x}^{3}-1$ \\
Fairness & Sense of fairness & $b / 2+1 / 2$ \\
\hline
\end{tabular}

maker does not actively try to avoid reaching the risk limits), risk avoidance (a market maker tries to avoid having a trading position close to the risk limits too frequently), lack of strategic thinking (a market maker adjusts bid and ask curves with some delay, more specifically one position too late), and fairness (a market maker sticks to a spread value of 1 , which is seen as fair and thus does not adjust the bid and ask curves sufficiently).

We have now simulated the behaviour of both rational and irrational market makers and their trading behaviour for five values of the $\sigma$ parameter. For each of the eight agent types (rational or biased - affected by one of the behavioural traits considered) we have run 100,000 simulations with different random numbers. For each simulation, we measured average profit per trading round and whether the market maker exceeded the risk limits in a given simulation (in which case, a market maker ceases trading and goes bankrupt). The simulation results are presented in Tables 17, 18, 19 and 20. 
Table 17 Average profit per trading round for agent type and different $\sigma$ values

\begin{tabular}{llllll}
\hline Bias/ $\sigma$ & 0.1 & 0.2 & 0.3 & 0.4 & 0.5 \\
\hline Rational & 0.4706 & 0.4706 & 0.4706 & 0.4706 & 0.4706 \\
Positive urgency & 0.4703 & 0.4695 & 0.4680 & 0.4660 & 0.4634 \\
Negative urgency & 0.4712 & 0.4717 & 0.4720 & 0.4722 & 0.4723 \\
Lack of premeditation & 0.4708 & 0.4709 & 0.4706 & 0.4702 & 0.4695 \\
Lack of perseverance & 0.4707 & 0.4705 & 0.4700 & 0.4692 & 0.4682 \\
Sensation seeking & 0.5119 & 0.5119 & 0.5119 & 0.5119 & 0.5119 \\
Risk avoidance & 0.4681 & 0.4681 & 0.4681 & 0.4681 & 0.4681 \\
Lack of strategic thinking & 0.5031 & 0.5031 & 0.5031 & 0.5031 & 0.5031 \\
Fairness & 0.5027 & 0.5027 & 0.5027 & 0.5027 & 0.5027 \\
\hline
\end{tabular}

Table 18 Standard deviation of profit per trading round for agent type and different $\sigma$ values

\begin{tabular}{llllll}
\hline Bias & 0.1 & 0.2 & 0.3 & 0.4 & 0.5 \\
\hline Rational & 0.0341 & 0.0341 & 0.0341 & 0.0341 & 0.0341 \\
Positive urgency & 0.0341 & 0.0340 & 0.0340 & 0.0340 & 0.0340 \\
Negative urgency & 0.0355 & 0.0366 & 0.0377 & 0.0388 & 0.0396 \\
Lack of premeditation & 0.0349 & 0.0355 & 0.0360 & 0.0362 & 0.0367 \\
Lack of perseverance & 0.0343 & 0.0346 & 0.0347 & 0.0349 & 0.0351 \\
Sensation seeking & 0.0806 & 0.0806 & 0.0806 & 0.0806 & 0.0806 \\
Risk avoidance & 0.0334 & 0.0334 & 0.0334 & 0.0334 & 0.0334 \\
Lack of strategic thinking & 0.0670 & 0.0670 & 0.0670 & 0.0670 & 0.0670 \\
Fairness & 0.0661 & 0.0661 & 0.0661 & 0.0661 & 0.0661 \\
\hline
\end{tabular}

Table 19 Ruin probability for agent type and different $\sigma$ values

\begin{tabular}{llllll}
\hline Bias $/ \sigma$ & 0.1 & 0.2 & 0.3 & 0.4 & 0.5 \\
\hline Rational & 0.0000 & 0.0000 & 0.0000 & 0.0000 & 0.0000 \\
Positive urgency & 0.0000 & 0.0000 & 0.0000 & 0.0000 & 0.0000 \\
Negative urgency & 0.0146 & 0.0288 & 0.0437 & 0.0572 & 0.0697 \\
Lack of premeditation & 0.0066 & 0.0141 & 0.0216 & 0.0286 & 0.0352 \\
Lack of perseverance & 0.0074 & 0.0152 & 0.0228 & 0.0293 & 0.0373 \\
Sensation seeking & 0.9581 & 0.9581 & 0.9581 & 0.9581 & 0.9581 \\
Risk avoidance & 0.0000 & 0.0000 & 0.0000 & 0.0000 & 0.0000 \\
Lack of strategic thinking & 0.7100 & 0.7100 & 0.7100 & 0.7100 & 0.7100 \\
Fairness & 0.6639 & 0.6639 & 0.6639 & 0.6639 & 0.6639 \\
\hline
\end{tabular}


Table 20 Standard deviation of ruin probability for agent type and different $\sigma$ values

\begin{tabular}{llllll}
\hline Bias & 0.1 & 0.2 & 0.3 & 0.4 & 0.5 \\
\hline Rational & 0.0000 & 0.0000 & 0.0000 & 0.0000 & 0.0000 \\
Positive urgency & 0.0000 & 0.0000 & 0.0000 & 0.0000 & 0.0000 \\
Negative urgency & 0.1198 & 0.1673 & 0.2044 & 0.2322 & 0.2546 \\
Lack of premeditation & 0.0812 & 0.1179 & 0.1453 & 0.1666 & 0.1842 \\
Lack of perseverance & 0.0859 & 0.1225 & 0.1491 & 0.1687 & 0.1895 \\
Sensation seeking & 0.2004 & 0.2004 & 0.2004 & 0.2004 & 0.2004 \\
Risk avoidance & 0.0000 & 0.0000 & 0.0000 & 0.0000 & 0.0000 \\
Lack of strategic thinking & 0.4537 & 0.4537 & 0.4537 & 0.4537 & 0.4537 \\
Fairness & 0.4724 & 0.4724 & 0.4724 & 0.4724 & 0.4724 \\
\hline
\end{tabular}

Table 21 Profit per trading round depending on the bias type, $\sigma=0.5$

\begin{tabular}{lcccc}
\hline & Estimate & SE & $\mathrm{t}$ value & $\operatorname{Pr}(>|\mathrm{t}|)$ \\
\hline (Intercept) & 0.471 & 0.000 & 2845.815 & 0.000 \\
Positive urgency & -0.001 & 0.000 & -5.773 & 0.000 \\
Negative urgency & -0.001 & 0.000 & -3.025 & 0.002 \\
Lack of premeditation & -0.001 & 0.000 & -2.302 & 0.021 \\
Lack of perseverance & -0.001 & 0.000 & -2.585 & 0.010 \\
Sensation seeking & 0.068 & 0.000 & 273.222 & 0.000 \\
Risk taking & -0.001 & 0.000 & -3.792 & 0.000 \\
Lack of strategic thinking & 0.035 & 0.000 & 139.849 & 0.000 \\
Fairness & 0.034 & 0.000 & 139.203 & 0.000 \\
\hline
\end{tabular}

Table 22 Ruin probability depending on the bias type, $\sigma=0.5$

\begin{tabular}{lrrrr}
\hline & Estimate & \multicolumn{1}{c}{$\mathrm{SE}$} & $\mathrm{t}$ value & $\operatorname{Pr}(>|\mathrm{t}|)$ \\
\hline (Intercept) & -0.016 & 0.001 & -11.320 & 0.000 \\
Positive urgency & 0.001 & 0.002 & 0.640 & 0.522 \\
Negative urgency & 0.000 & 0.002 & 0.064 & 0.949 \\
Lack of premeditation & -0.001 & 0.002 & -0.543 & 0.587 \\
Lack of perseverance & 0.001 & 0.002 & 0.401 & 0.689 \\
Sensation seeking & 1.425 & 0.002 & 668.502 & 0.000 \\
Risk taking & -0.025 & 0.002 & -11.681 & 0.000 \\
Lack strategic thinking & 0.742 & 0.002 & 348.486 & 0.000 \\
Fairness & 0.711 & 0.002 & 338.994 & 0.000 \\
\hline
\end{tabular}


We can observe that either of the biases referred to may lead to worse results with the same ruin probability (e.g. positive urgency) or may lead to better results but with increased ruin probability (e.g. sensation seeking).

We have also considered the situation that a market maker may have many biases present at the same time. The simplest way to model such a situation is to assume that a final bid/ask quote is the weighted average of the bid/ask spreads that would have been quoted by a hypothetical market maker having only one single bias $b=\sum_{i=1}^{9} b_{i} w_{i}$ and respectively $a=\sum_{i=1}^{9} a_{i} w_{i}$. The weights determine the relative importance (intensity) of the given bias. Of course, more complex mechanisms are also possible, such as those involving a hierarchy of biases.

In particular, we constructed 200 hypothetical market makers with different weights of the biases. We have used the Sobol sequence for this purpose, similar to that described in the Sect. 3.1. To expand further, for each consecutive nine-element vector of the Sobol sequence $x_{i}$, we have constructed relevant weights by the following transformation $w_{i}=x_{i} / \sum_{i=1}^{9} x_{i}$. The first weight $w_{1}$ represents the share of rationality in the decisions of the market makers. This variable was omitted in the linear regression to avoid collinearity. We only considered the case with the parameter $\sigma=0.5$. The regression results are presented in Tables 21 and 22. The general picture is similar, namely that those biases that lead to a higher average profit per round when trading — sensation seeking, lack of strategic thinking and fairness — also lead to a higher probability of ruin for market makers.

\section{References}

Amihud Y, Mendelson H (1980) Dealership market: market-making with inventory. J Financ Econ 8(1):3153

Barto K (2019) MuMIn: multi-model inference. https://CRAN.R-project.org/package=MuMIn, r package version 1.43 .6

Bratley P, Fox BL (1988) Algorithm 659: implementing Sobol's quasirandom sequence generator. ACM Trans Math Softw (TOMS) 14(1):88-100

Brocklebank S, Lewis GJ, Bates TC (2011) Personality accounts for stable preferences and expectations across a range of simple games. Personal Individ Differ 51(8):881-886

Brooks ME, Kristensen K, van Benthem KJ, Magnusson A, Berg CW, Nielsen A, Skaug HJ, Machler M, Bolker BM (2017) glmmtmb balances speed and flexibility among packages for zero-inflated generalized linear mixed modeling. R J 9(2):378-400

Chakrabarty B, Moulton PC (2012) Earnings announcements and attention constraints: the role of market design. J Acc Econ 53(3):612-634

Christophe D, Petr S (2014) randtoolbox: generating and testing random numbers. R Foundation for Statistical Computing, Vienna

Cimon D, Garriott C (2019) Banking regulation and market making. J Bank Finance

Cyders MA, Smith GT, Spillane NS, Fischer S, Annus AM, Peterson C (2007) Integration of impulsivity and positive mood to predict risky behavior: development and validation of a measure of positive urgency. Psychol Assess 19(1):107

De Jong F, Rindi B (2009) The microstructure of financial markets. Cambridge University Press, Cambridge

Fagerlin A, Zikmund-Fisher BJ, Ubel PA, Jankovic A, Derry HA, Smith DM (2007) Measuring numeracy without a math test: development of the subjective numeracy scale. Med Decis Mak 27(5):672-680

Garety PA, Hemsley D, Wessely S (1991) Reasoning in deluded schizophrenic and paranoid patients: biases in performance on a probabilistic inference task. J Nerv Mental Dis

Garman MB (1976) Market microstructure. J Financ Econ 3(3):257-275

Germain L, Rousseau F, Vanhems A (2014) Irrational market makers. Finance 35(1):107-145 
Glosten LR, Milgrom PR (1985) Bid, ask and transaction prices in a specialist market with heterogeneously informed traders. J Financ Econ 14(1):71-100

Goldstein MA, Hotchkiss ES (2019) Providing liquidity in an illiquid market: Dealer behavior in us corporate bonds. J Financ Econ 135:16-40

Harlé KM, Sanfey AG (2010) Effects of approach and withdrawal motivation on interactive economic decisions. Cogn Emot 24(8):1456-1465

Harris LE, Panchapagesan V (2005) The information content of the limit order book: evidence from nyse specialist trading decisions. J Financ Mark 8(1):25-67

Hasbrouck J (2007) Empirical market microstructure: the institutions, economics, and econometrics of securities trading. Oxford University Press, Oxford

Korajczyk RA, Murphy D (2018) High-frequency market making to large institutional trades. Rev Financ Stud 32(3):1034-1067

Lejuez CW, Read JP, Kahler CW, Richards JB, Ramsey SE, Stuart GL, Strong DR, Brown RA (2002) Evaluation of a behavioral measure of risk taking: the balloon analogue risk task (bart). J Exp Psychol Appl 8(2):75

GmbH Limesurvey (2012) LimeSurvey: an open source survey tool. LimeSurvey GmbH, Hamburg

Lipkus IM, Samsa G, Rimer BK (2001) General performance on a numeracy scale among highly educated samples. Med Decis Mak 21(1):37-44

Madhavan A (2002) Market microstructure: a practitioner's guide. Financ Anal J 58(5):28-42

Market Squared Ltd (2010) Volcube trading platform. http://www.volcube.com

McCulloch CE, Neuhaus JM (2005) Generalized linear mixed models. Encycl Biostat. https://doi.org/10. 1002/0470011815.b2a10021

Millisecond Software LLC (1999) INQUISIT 4.0. https://www.millisecond.com/download/library/

O’hara M (1997) Market microstructure theory. Wiley, New York

Poprawa R (2016) Polska adaptacja upps-p skali impulsywnego zachowania oraz jej znaczenie w predykcji wybranych eksternalizowanych problemów i zaburzeń. Przegląd Psychologiczny 59(1):95-116

Stoll HR (1978) The supply of dealer services in securities markets. J Finance 33(4):1133-1151

Whiteside SP, Lynam DR (2001) The five factor model and impulsivity: using a structural model of personality to understand impulsivity. Personal Individ Differ 30(4):669-689

Publisher's Note Springer Nature remains neutral with regard to jurisdictional claims in published maps and institutional affiliations. 